\title{
Scratching suspected porokeratosis lesion, simple and quick maneuver that facilitates its diagnosis
}

\section{Paulo Ricardo Martins Souza, Thaís Marques Furtat, Nicole Reinisch, Paulo Henrique Pacheco Dario}

${ }^{1}$ Dermatology Service of Santa Casa de Misericórdia de Porto Alegre Hospital - Porto Alegre (RS), Brazil, ${ }^{2}$ Post-Graduation Program in Health and Behavior, Catholic University of Pelotas (UCPEL) - Pelotas (RS), Brazil, ${ }^{3}$ Medicine

Graduation - Federal University of Pelotas (UFPEL) - Pelotas (RS), Brazil

Corresponding author: Dr. Nicole Reinisch, E-mail: nicolereinisch23@gmail.com

\begin{abstract}
Porokeratosis are morphologically distinct keratinization disorders, characterized clinically by papules or hyperkeratotic plaques surrounded by a linear raised border. Sometimes the border (the most characteristic change in porokeratosis, and practically the definition of diagnosis) is not easily identifiable. We demonstrated a clinical maneuver that facilitated the visualization of this more typical aspect in frame. A wooden tongue depressor was used to gently scratch one of the lesions. This maneuver revealed a desquamative halo in the hyperkeratotic lesion - better identifying the clinical aspect typical of the porokeratosis. The use of scratching may play a fundamental role in the diagnostic suspicion of porokeratosis and should be applied whenever the clinical history suggests this hypothesis as a differential diagnosis.
\end{abstract}

Key words: Porokeratosis; Keratotic lesions; Cornoid lamella

\section{INTRODUCTION}

Porokeratosis are morphologically distinct keratinization disorders, characterized clinically by papules or hyperkeratotic plaques surrounded by a linear raised border. Histologically, a thin column of paracerathotic cells extends throughout the corneal extract and is seen in all variants. This histopathological finding, known as the cornoid lamella, corresponds to clinically demonstrable hyperkeratosis [1-10]. Sometimes the border (the most characteristic change in porokeratosis, and practically the definition of diagnosis) is not easily identifiable. We demonstrated a clinical maneuver that facilitated the visualization of this more typical aspect in frame.

\section{CASE REPORT}

A 48-year-old female patient with multiple keratotic lesions for more than 20 years in the upper limbs with a characteristic appearance of actinic keratosis. Due to the early onset of the disease, actinic porokeratosis or disseminated superficial porokeratosis was suspected. In the search for lesions that identified porokeratosis, a wooden tongue depressor was used to gently scratch one of the lesions (Fig. 1). This maneuver revealed a desquamative halo in the hyperkeratotic lesion (Fig. 2) - better identifying the clinical aspect typical of the porokeratosis.

\section{DISCUSSION}

Porokeratosis include a heterogeneous genetic group of disorders that represent different phenotypic expressions of the same gene defect, which is inherited mainly in an autosomal dominant way $[2,3]$. The disease usually manifests itself in the third or fourth decades of life with a feminine preponderance. The tendency to develop these lesions is provided by two genes already mapped: DSAPl on chromosome 12q23.2-24.1 and DSAP2 on chromosome 15q25.1-26.1 [4].

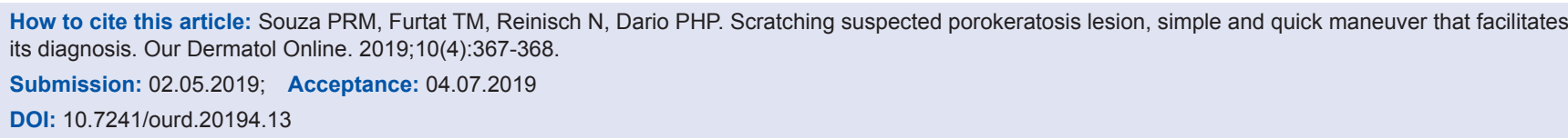




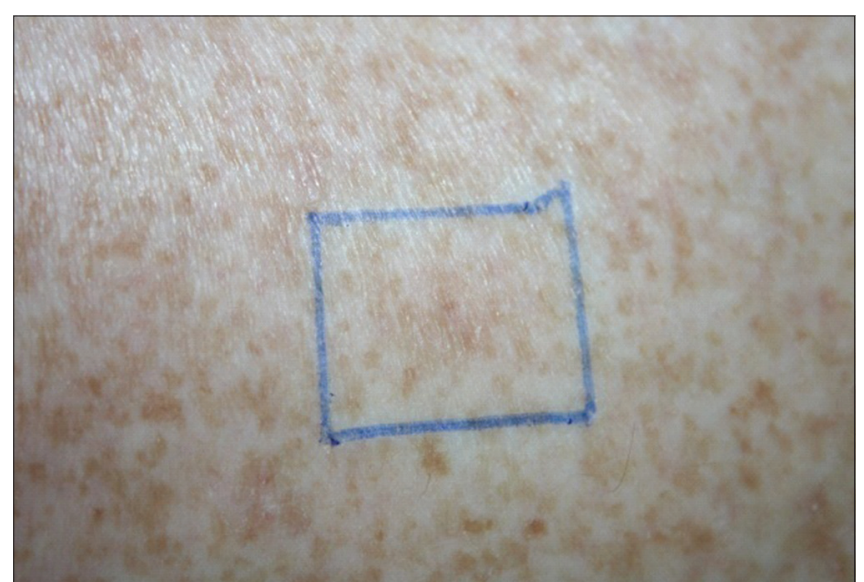

Figure 1: The suspected lesion, without the typical desquamative halo of the porokeratosis.

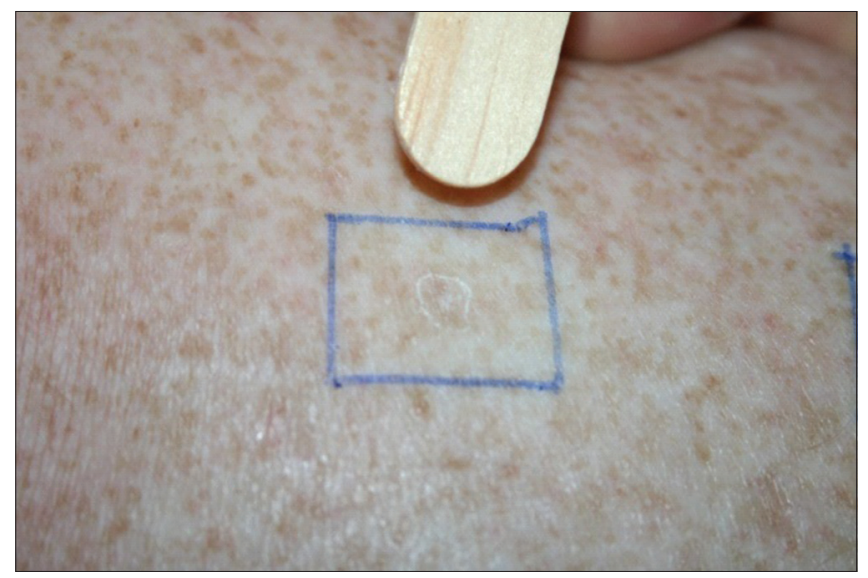

Figure 2: Typical desquamative halo after scratch the lesion with a wooden tongue depressor.

Although reports of transformation in non-melanoma skin cancer $[1,3,5]$, the reported frequencies of malignant transformation (between $6.8 \%$ and $11.0 \%$ ) are likely to be overestimated [6].

Dermatoscopy is a non-invasive and rapid auxiliary method, increasingly common in clinical practice, capable of improving accuracy in the diagnosis of pigmented lesions [7].

At the dermatoscopic examination, the cornoid lamella appears as a thin white border lined with brown pigmentation. The atrophic center of an injury often demonstrates a white area with red dots, globules and lines representing capillaries [8]. Unfortunately, the most characteristic change in porokeratosis, the border framing the lesion, is not always present at physical and dermatoscopic examination [9].
The onset of lesions before the age of 30 led to the suspicion that it was not keratoseactin, our initial clinical impression. With the hypothesis of porokeratosis, the scraping of a suspected area identified a clearer halo and favored the diagnosis, confirmed later histologically. We suggest this simple maneuver that facilitates diagnosis in some cases where the porokeratosis frame is not so obvious.

\section{CONCLUSION}

Therefore, the use of scratching may play a fundamental role in the diagnostic suspicion of porokeratosis and should be applied whenever the clinical history suggests this hypothesis as a differential diagnosis.

\section{Consent}

The examination of the patient was conducted according to the Declaration of Helsinki principles.

\section{REFERENCES}

1. O'Regan GM, Irvine AD.Porokeratosis. In: Fitzpatrick TB, Eisen AZ, Wolff K, Freedberg IM, Austen KF, editors. Dermatology in general medicine. $7^{\text {th }}$ ed. New York: McGraw-Hill; 2008. p. 442-6.

2. Kanitakis J. Porokeratoses: an update of clinical, aetiopathogenic and therapeutic features. Eur J Dermatol. 2014;24:533-44.

3. Ferreira FR, Santos LDN, Tagliarini FANM, Alvarenga Lira ML. Poroqueratose de Mibelli - revisão da literatura e relato de um caso. An Bras Dermatol. 2013;88:S179-82.

4. Weidner T, Illing T, Miguel D, Elsner P. Treatment of porokeratosis: a systematic review. Am J Clin Dermatol. 2017;18:435-49.

5. Filho FB, Quaresma MV, Vendramini DL, Kac BK, Leal F, Azulay DR. Poroceratose superficial diseminada. Rev SPDV. 2013;71:501-5.

6. Gutierrez EL, Galarza C, Ramos W, Tello M, De Paz PC, Bobbio L, et al. Facial porokeratosis: A series of six patients. Australas J Dermatol. 2010;51:191-4.

7. Bastos CA. Non-traditional Indications in dermoscopy. Surg Cosmet Dermatol. 2012;4:203-5.

8. Zaballos P, Puig S, Malvehy J. Dermoscopy of disseminated superficial actinic porokeratosis. Arch Dermatol 2004;140:1410.

9. Chernosky ME, Freeman RG. Disseminated superficial actinic porokeratosis (DSAP). Arch Dermatol 1967;96:611-24.

10. Ferreira FR, Santos LDN, Tagliarini FANM, Alvarenga Lira ML. Poroqueratose de Mibelli - revisão da literatura e relato de um caso. An Bras Dermatol. 2013;88:S179-82.

Copyright by Paulo Ricardo Martins Souza, et al. This is an open-access article distributed under the terms of the Creative Commons Attribution License, which permits unrestricted use, distribution, and reproduction in any medium, provided the original author and source are credited.

Source of Support: Nil, Conflict of Interest: None declared. 